\title{
Osteopathic medicine: The profession's role in society
}

\author{
IRVIN M. KORR, PhD
}

Virtually all professions - medicine, engineering, architecture, law, education, nursing, dentistry, journalism - came into existence in response to widely, even universally, felt societal needs, and they have evolved or vanished from the scene as those needs changed and as technology advanced. In recent years, we have witnessed and welcomed the appearance and growth of new services, such as computer science, and scarcely marked the obsolescence of others, such as telegraphy, as they have come, flourished, or faded away as social, cultural, demographic, technological, and other changes occurred.

\section{The founding of the profession: An accident of history?}

The profession of osteopathic medicine is one of a very few exceptions to the foregoing generalization. It came into existence not to meet a generally recognized need, but to meet a need perceived at first by one man and by a small group of others with whom he shared his perception. What was the need Andrew Taylor Still perceived? He saw the need to "improve our present system" of medicine-that of the late 19th century-by placing it on a "more rational and scientific basis." The quoted phrases are from the charter of the first school of osteopathy in 1892 , which marked the founding of the profession.

As is well documented, it had not been the founder's intention to start a new profession, but rather to reorient medicine in general to a philosophy of practice that placed emphasis on the treatment of the patient as a whole,

Reprint requests to Irvin M. Korr, $\mathrm{PhD}, 740$ Oakwood Trail, Fort Worth, TX 76112. necessitated by the intercommunication and binding of all body parts into a single unity; on the special place of the musculoskeletal system in that community of body systems; on the inherent self-regulatory, health-maintaining, and health-restoring mechanisms as the very source of health; and on positive health as the natural state and as medicine's highest objective.

As was said, the intention was not to establish a competing medical profession but to reform the existing one. The times, however, could not have been less auspicious for reform. The prevailing diseases and causes of premature death had long been the infectious diseases, plagues, and epidemics. But with the then recent discovery of bacteria as the "causes" and with the promise of "cures" by molecular "magic bullets," it seemed to the medical establishment of the day that freedom from disease and utopian health would soon become a reality as the diseases were picked off one by one. This was hardly the time for any reform, much less for the one being proposed.

Under the circumstances, Still and the first recruits to his cause, determined as they were, had no alternative but to start a new profession that would demonstrate what medicine could be like. In the real sense, therefore, the establishment of a separate medical profession was entirely an accident of history. The issues that divided the two professions were - and areof the sort that are ordinarily debated, and usually resolved, within a single profession.

Thus began the almost century-long, heroic, and ultimately triumphant struggles: first for the right to practice in each state, largely lim- 
ited to manipulation; then for full practice rights (won, ironically, by demonstrating competence according to allopathic criteria, and achieved in all 50 states only as recently as 1973); and finally, for legislative and other kinds of parity with the dominant profession, while preserving the "distinctiveness" that is said to demand existence as a separate profession. There are no further rights, privileges, and recognitions to be won. Achievement of parity has been the ultimate triumph. Or has it?

\section{The role of the profession is more than the sum of individual DO roles}

Having come into existence without invitation, so to speak, in the absence of a widely, much less universally, appreciated need for its services, the osteopathic medical profession has been continually challenged throughout its history to explain itself and to defend its raison d'être. What, aside from parity, are its goals? For what purpose has it struggled so long and so tenaciously for parity? Having achieved parity, what now? What, as an organized profession, is the osteopathic medical profession seeking to accomplish on behalf of human health, beyond providing additional numbers of physicians? What needs, the public keeps asking in various ways, does the osteopathic profession meet or purport to meet that are not met, or likely to be met, by the profession known, respected, and relied on for centuries as the medical profession, as Medicine itself? In other words, is another medical profession really necessary?

Not only has the achievement of parity failed to satisfy the questioners and to soften the questions, the questions have become more insistent and incisive, and more difficult to answer. What answers can be offered? What answers have been offered?

In 1892, the founders of the osteopathic medical profession saw this profession's purpose to be that of improving the whole system of medicine by introducing and implementing what they saw as a neglected body of fundamental principles underlying human health and illness. What does today's osteopathic medical profession see as its purpose, its function? Does it still see itself as a movement, "an American reformation?"1 Or is today's purpose, as stated in the American Osteopathic Association's brochures, ${ }^{2,3}$ to offer the public and the individual a choice of physicians-an MD or a DO? If so, what is the choice, other than of academic degree? According to the American Osteopathic Association's public statements, the "choice" is described by the following facts:

- DOs, like MDs, are "complete" physicians, qualified and licensed to practice in all recognized branches of clinical medicine.

- Their education is essentially the same, except that DOs receive "additional training" in diagnosis and treatment of the musculoskeletal system, subsumed under "manipulative treatment." "Osteopathic medicine offers something more-not something else."2 (Like the cherry on the ice cream sundae.)

- They take the same examinations for licensure.

- A larger percentage of DOs than MDs are in general practice and primary care because, it is said, of their emphasis on treating the whole person.

- A larger percentage of DOs than MDs practice in small communities and rural areas.

In terms of services for which they are qualified (which is the question in the prospective patient's mind) the choice, then, is that while both MDs and DOs are "complete" physicians, DOs are a bit more complete in that, in addition to everything else, they offer manipulative treatment. But does manipulation characterize the osteopathic medical profession? How "distinctive" a feature is manipulation?

In the first place, one must acknowledgeand cheer-the increasing numbers of MDs who have received and are receiving training in manipulation, often under osteopathic auspices, and who make it a substantial aspect of their practice. Furthermore, at least two other professions have long practiced and even specialized in manipulation. The continual proliferation and growth of interprofessional organizations dedicated to the advancement of manipulative medicine and the exploration of its scientific foundations is noteworthy. The North American Academy of Musculoskeletal Medicine (NAAMM) and the International Federation of Manual Medicine (FIMM), of which 
NAAMM is a member, are prominent examples of this movement.

In the second place, and perhaps even more important, osteopathic manipulative treatment (OMT) is today a significant part of the practice of only a minority of osteopathic physicians, perhaps even a small minority. This fact is often brought home to me when friends, members of my lecture-audiences, MDs, fellow scientists, or others in various parts of the United States call on me to recommend a DO in their vicinities for manipulative care. I learned long ago that I can offer the inquirer little assurance that a geographic list of DOs gathered from the AOA Yearbook and Directory, or even a list of osteopathic general practitioners, will include even one who will meet their requirements. No less significant is my experience as a frequent lecturer on the physiological mechanisms underlying OMT. In recent years, my services have been sought much more by interprofessional and nonosteopathic organizations and institutions than by those of the osteopathic medical profession.

It should be clear from the circumstances described in the preceding two paragraphs that manipulation - even superb manipulationdoes not distinguish the osteopathic medical profession. As for the osteopathic philosophy, even given its growing scientific validation, its value is in its clinical expression and not in its avowal. A review of osteopathic medicine's history shows that the more nearly that parity has been secured and the more "complete" its practice, the narrower the margin of its "distinctiveness." The profession seems to be in the position of seeking to prove its distinctiveness to justify its existence as another "choice," but without being too distinctive, something more, not something else.

This also signifies that the raison d'etre is to be found not so much in what individual DOs do that MDs do not, or where they practice, but in what DOs do collectively, as an organized, fully qualified medical profession and in what they seek to accomplish on behalf of the health of the American people. What health needs does the osteopathic medical profession purport to meet that are not being met, or likely to be met, by any other professionwhich, in general, is the reason for being of any profession? What, indeed, is its function as a profession? This is a crucial question, to be addressed by the organized aggregate because a profession, like the human organism, is more-far more-than the sum of its components, and what the profession, like the person, strives for determines how the parts serve.

In a recent JAOA editorial, ${ }^{4}$ titled "Correcting the misperceptions surrounding osteopathic medicine," AOA Editor-in-Chief Thomas Wesley Allen, DO, reviewed the impressive progress made by the osteopathic medical profession during the past 20 years. "Despite all these accomplishments," he says, "our role in society remains greatly misunderstood." (Emphasis added.) After a century, he concludes, "osteopathic medicine remains, perhaps, one of the world's best kept secrets. It's time to share our secret with society at large." Indeed, it is well past time.

But does the osteopathic medical profession know, and agree on, what its "secret" is? Society can hardly be expected to be clear about the profession's "role in society" before the profession is clear. Perhaps at this stage of the profession's history, clarity should take precedence over parity - clarity as to the osteopathic medical profession's real distinctiveness.

\section{Thirty years of change in the profession}

The theme of the 1959 Annual Convention of the AOA was "Unfolding Horizons." (At the time, certainly looming on the osteopathic medical profession's horizon was the threatening secession of its largest segment, California.)

In the keynote address, titled "The function of the osteopathic profession-a matter for decision," I urged the profession to engage that issue, and I dared to suggest a worthy function, an increasingly urgent one, and one for which the profession was eminently suited by virtue of its history, its philosophical orientation, and its technology.

The question, What is the function of the osteopathic medical profession? has remained unanswered in that long interval, and apparently unasked. Indeed, long-time study of osteopathic medical literature, old, recent, and current, and my observations during an intimate acquaintance with the profession extending over almost half of its entire history (and more 
than half of mine) indicate that the question has not been addressed in any concerted manner since the profession's earliest years. Nevertheless, the profession has continued to make decision after momentous decision while living in ambiguity about its function-its role in society.

Let us see now what changes have occurred in the profession in the intervening 30-plus years. In 1959, the osteopathic medical profession was still struggling for full practice rights in several states. Federal legislation was still discriminatory in several key areas. The profession was confronting the threat of piecemeal "amalgamation," most imminently in California. There were six osteopathic medical colleges (still retaining "osteopathy" in their names, and one soon to be lost). None was university affiliated or publicly funded. Funding sources, always insufficient, were mainly tuition and student fees, contributions by DOs, directly or through dues, and earnings of college-operated hospitals and clinics. Research grants, other than by the AOA, were still few.

In the spring of 1959 , the six colleges graduated 467 new DOs, soon to begin their internships. There were fewer than 11,000 DOs in active practice. The 135 osteopathic hospitals offered far more AOA-approved internships than could be filled by new graduates. Competition for new graduates was keen. Indeed, in my address, I pointed to the severe imbalance between the profession's investment in hospitals and that in its very source, the colleges. College administrators often complained that their clinical faculties were being "raided" by private osteopathic hospitals seeking additional staff members.

By 1962, that situation was exacerbated following the closing of the College of Osteopathic Physicians and Surgeons in Los Angeles, and only 363 new DOs became available that spring. Osteopathic physicians had only recently won the legal right (though only partially implemented) to practice in public hospitals as "complete" physicians and surgeons, but not yet the privilege of serving as medical officers in the armed forces. And even the degree of "completeness" was questionable because not all the specialties were then repre- sented in osteopathic residency programs and specialty colleges.

By 1989 , the number of osteopathic colleges had long increased, from five to 15 . Most of the new colleges were affiliated with universities or publicly supported or both (and "osteopathic medicine" had replaced "osteopathy" in the names of all the colleges). In the spring of 1989 , the 15 colleges graduated 1689 new DOs, soon to join the 22,000 in active practice (of the approximately 30,000 listed in the $\mathrm{Di}$ rectory). Osteopathic medicine had become "the fastest growing profession." Practice rights had long been granted by the last holdout state. Many osteopathic physicians were serving, and with distinction, as medical officers in the uniformed services, including the Public Health Service. Many, with AOA approval, were receiving all of their postdoctoral and specialty training in military hospitals throughout the nation. All federal legislation related to healthcare, its regulation, and public funding gave equal recognition to osteopathic medicine as a fully qualified and participating medical profession. Every official recognition sought by the osteopathic medical profession had been granted.

Today, the profession can boast that it is really complete. Currently, there are 48 accredited specialties and subspecialties (the "distinctive" one of which is Osteopathic Principles and Practices), "with residency programs, which, once completed, qualify the physician for eligibility leading toward eventual certification." 6

In recent years, however, it has become increasingly difficult to characterize the AOAaccredited postdoctoral educational programs as osteopathic internships and residencies. This difficulty has been occasioned by the reversal of the imbalance that existed between colleges and hospitals in 1959, and for some years thereafter. In the years in which the threefold multiplication of colleges occurred, the number of osteopathic hospitals increased only by one fourth, from 135 to 172 -in the face of a fourfold increase in the number of graduates. And the imbalance builds as the current trend from inpatient care to outpatient care accelerates, and as more and more osteopathic hospitals, especially in smaller commu- 
nities and inner cities, suffer closures, conversions, and acquisitions. Ironically, the smaller community hospitals are the very ones that are best suited for postgraduate training in the primary care areas, namely, general practice, pediatrics, and general internal medicine.

The graduates-no longer the hospitalshad suddenly been thrust into competition with each other for the too few osteopathic internships and residencies. Under the circumstances, the AOA had little alternative but to accredit increasing numbers of nonosteopathic postdoctoral education programs, in addition to those under military auspices already accredited, in order to accommodate the swelling ranks of DOs clamoring for training.

In a recent, well-documented article, Mark Cummings, $\mathrm{PhD},{ }^{7}$ addressed this issue with startling and even alarming impact. Large and increasing numbers of DOs are being pulled into a "vacuum" in allopathic postgraduate training programs, especially in the primary care disciplines of family medicine, pediatrics, and general internal medicine. The steadily enlarging vacuum is created by the increasing aversion of new MDs to primary care in favor of surgical and subspecialty fields. As confirmed in another recent article, ${ }^{8}$ by 1987 , more than twice as many DOs were in allopathic family medicine residencies as in AOAapproved programs. Indications are that the ratio in 1990 is considerably larger than two out of three.

This trend is by no means limited to primary care. In the 4-year period between 1985 and 1988, the number of DOs in allopathic programs in a variety of specialties increased by 770 , three times the increase of 228 in corresponding osteopathic programs. ${ }^{7}$ In addition to family medicine, pediatrics, and general internal medicine, these specialties included anesthesiology, emergency medicine, neurology, obstetrics and gynecology, pathology, physical medicine and rehabilitation, psychiatry, and surgery.

As Cummings shows, osteopathic graduates are not being as cordially welcomed into allopathic programs in the surgical and medical subspecialties. These, however, are the very disciplines for which the handful of large osteopathic hospitals in major cities are quali- fied (in contradistinction to the shrinking number of small community hospitals, which are more oriented to primary-care disciplines). As a result, a remarkable and unsettling "crossover" (Cumming's term) is in process, one that casts in doubt the proud claim of the osteopathic medical profession to being the major source of general practitioners. "What could develop," says Cummings, "is a lopsided educational structure in which DOs interested in surgical specialties train in osteopathic hospitals, while those interested in all other medical disciplines train in allopathic residencies." (This crossover has other dire implications for the osteopathic medical profession, which are beyond the purpose of this article, but which demand early attention. These implications include the increasing tendencies for osteopathic physicians who have completed allopathic residencies to drift away from their osteopathic affiliations and to seek allopathic certification; to reject small-town and rural practice; and to refer their patients to allopathic hospitals, thus hastening the demise of smaller community-based osteopathic hospitals, which depend so heavily on such referrals, and which have been the base for training in primary-care areas.)

While these developments could be viewed as acknowledgment of the high quality of osteopathic (undergraduate) medical education, it has been at further cost to distinctiveness.

\section{Thirty years of change in the American health scene}

What happened with respect to American health during the same 30 -year period? The decline, which had begun before the turn of the century, in the enormous numbers of deaths of infants, children, and young adults due to acute infectious diseases, had accelerated in the first half of the 20th century. By 1959 , progress had been such that a larger percentage of live-born infants could be expected to survive to their 50th year of life (almost $90 \%$ ) than in 1900 survived the first year of life $(84 \%)$ !

Welcome as this advance was, it had become painfully evident by mid-century that the survival of more and more people to the later decades of life had brought with it another, and 
rapidly growing, health problem. The American people and their healthcare system were experiencing an exchange of unanticipated magnitude, between quick and early mortality on the one hand, and later, long-term morbiditythe chronic degenerative diseases-on the other. (Some, perhaps cynically, thought that quick and early death was much more merciful to the victim, the family, and the national economy than the long and lingering one.)

Between 1900 and 1959, life expectancy at birth had increased by about 22 years to age 70 , and the percentage of people over 65 years of age had tripled (from about $3 \%$ to more than $9 \%)$. Unfortunately, the more that the average length of life increased, the greater the opportunity for minor impairments and slowacting factors to take their toll, for symptoms to appear and for various forms of functional breakdown and decompensation to develop. All of the organ systems are at risk and vulnerable, and cardiovascular diseases, cancer, and stroke dominated the health scene more and more. In effect, we were experiencing an unexpected and troubling paradox: the lower the mortality rates, the higher the morbidity rates. The burden of long-term illness among the elderly had become so enormous that steps had to be taken, and were taken, that culminated a few years later in the Medicare program, designed to make healthcare more readily available and affordable to the burgeoning older population.

The problem has rapidly increased in severity in the intervening years despite the nation's huge monetary investment and despite the many dramatic advances in medical technology. The life expectancy at birth (average length of life) is now more than 75 years; about $12 \%$ of the population is older than 65 years, and those older than 85 years make up the fastest growing age segment. A large majority, $80 \%$ or more of those older than 65 years, are afflicted with one or more chronic impairments. For example, $44 \%$ suffer from one or another form of arthritis; $38 \%$ are hypertensive; $25 \%$ are mentally ill; and numerous others are handicapped by sensory and motor losses and other disabilities.

The average senior citizen sees physicians more often, is hospitalized twice as often, stays twice as long, and consumes twice as many prescription drugs as those younger than 65 years. The illnesses of the $12 \%$ of the population who are now older than 65 years are responsible for one third of the nation's total expenditure for healthcare. Per capita expenditures for the elderly are 3.5 times those of the population younger than 65 -years. The people older than 65 years are expected to compose $20 \%$ of the population (one in five!) in the year 2030 , and their care to account for $50 \%$ of the nation's healthcare bill. ${ }^{9}$

In short, the amount of illness, suffering, disability, and burdens on family care-givers is staggering and still increasing; the cost to the nation is enormous-more than $\$ 600$ billion in 1989 (12\% of the gross national product) and increasing at rates of $\$ 50$ billion to $\$ 70$ billion per year. By such additional criteria as the numbers of persons engaged in healthcare, cost of facilities, equipment, and their operation and maintenance, the healthcare industry is the third, possibly the second, largest industry in the United States.

\section{The perfect role in society for the osteopathic medical profession}

The increasingly overwhelming problem of chronic disease was precisely the problem that in $1959^{5}$ and again in $1962^{10}$ (after the California debacle) I urged the osteopathic medical profession to engage. Why? Because the problem was not being confronted in a way that it required-a way for which the osteopathic medical profession was "distinctively" suited, as I have said, by virtue of its history and traditions, its philosophical perspectives of health and disease, by the technology that it has developed to a high degree of effectiveness, and even by the maneuverability that its relatively small size made possible. Let me explain.

Unlike the infectious diseases, the chronic degenerative diseases cannot be ascribed to single, eradicable "causes." Their etiologies are extremely complex. They are the products of whole constellations of factors - of the ways and the circumstances in which one lives and has lived. (Even smoking is not the cause of lung cancer because only a small minority of smokers become victims; obviously, it is but one of a number of contributing factors. As a matter 
of fact, the same reasoning applies even in infectious disease, as Pasteur himself pointed out; the "host" must provide a hospitable "terrain" for the microbe.) The contributing factors may be in a variety of realms, subjective as well as objective-genetic, developmental, psychological, perceptual, sociocultural, structural, nutritional, environmental, and so forth. The degenerative diseases are the totally natural culmination of living on physiological paths that are unfavorable in various ways. The only hope for enduringly effective treatment-and for prevention, that is, lowered probabilityis to move patients and the not-yet-sick to more favorable life paths.

This whole-person approach is at the heart of osteopathic medical care, its very essence. Admittedly, control of all or most of the causative factors is beyond the power even of teams of able physicians. And some factors are changed only with great difficulty, such as lifetime habits, beliefs, or diets. Others, such as economic conditions and environment, are beyond control by individuals. The strategy, however, is not to remake the person and his or her life. It is to give corrective attention to those factors that are amenable to change and of sufficient "weight" to shift the balance toward recovery and to higher levels of health.

In this regard, also, the osteopathic medical profession is at enormous advantage. I refer to the science and art of musculoskeletal ("structural") diagnosis and OMT, which it has developed to an unprecedented level of precision and effectiveness. Still caught up in the archaic concept of single, specifistic etiology, too many DOs in my experience have dismissed it as of questionable value for lack of "proof" that somatic dysfunction is "the cause" of this or that disease or of any disease.

What is overlooked in this perspective is the fact, demonstrated by research (see reference 11 , for example, for a summary) and by skilled practice, that its etiological role is in exaggerating the deleterious impact of other negative factors in and around the person, directing that impact to selected organs and tissues, and that, through nervous and fluid channels, it impairs the regulatory, defensive, and healing mechanisms of the body. Because of the peculiar susceptibility of the human framework to com- pressive and torsional forces, somatic dysfunction has a high incidence in humans, and a high potential for contributing to pathophysiological havoc. Fortunately, it is noninvasively accessible and responsive to manipulative skills.

When osteopathic physicians who are skilled in OMT are also able, themselves or in collaboration with others, to provide guidance for their patients in behavioral, psychosocial, and nutritional realms, they have command of a powerful lever for moving the whole person, and not just a part of the body, to a physiological path on which illness is less likely, and recovery from existing illness more rapid, complete, and enduring. Osteopathic principles are in themselves reliable guides to healthful living. ${ }^{12}$

Were this to become the strategy of the osteopathic medical profession, it would, in itself, as an example to the entire world, be a historic contribution to the treatment and prevention of the diseases that plague the United States today, and that threaten to do so for decades to come. It would be less spectacular, perhaps, than organ transplants, artificial hearts, and other technological feats, but of much wider impact on the health, wealth, and welfare of this nation and its people. Medicine must more and more turn from intervention in biological process and learn to free the body's indwelling healthcare system of impediments and to evoke the body's own medicines, scores of which have been identified in recent years. Having, from its beginning, emphasized in its practice the inherent health-maintaining and the health-restoring powers, the osteopathic profession has long had the opportunity to lead this movement-even while pursuing technological parity and completeness. It would establish a distinctive and honored role in society beyond all question.

I have no illusion, of course, that the profession's ongoing thrust(s) or the practice habits of its members can be quickly redirected. One cannot expect the profession's many-year drive for "completeness" of its armamentarium of specialties, subspecialties, and high technologies (in which it has little distinctive contribution to make) can quickly revert to care of the complete patient. One can only regret 
that in its relentless drive for diversification, resulting in numerous competing turfs, the profession seems to have lost sight of the purpose and principles that would bind it together into a unified, powerful, and truly distinctive instrument serving human health. Only by a highly selective focus of its resources can the osteopathic medical profession resolve its crisis in postdoctoral education and emerge, not only undefeated, but triumphantly, rather than defensively, distinctive.

On the contrary, if the return to fundamentals, to the essence of osteopathic medicine, is to be accomplished, it must be done through the education and training of future osteoapathic physicians; that is, through the colleges of osteopathic medicine, through curricula that focus on the person as a whole and on strategic "manipulation" of the factors in and around the person that determine his or her ability to stay well and to get well. ${ }^{13}$ It is regrettable that one of the colleges of osteopathic medicine, which was bold enough to commit itself to developing such an educational program ${ }^{14}$ received much less acknowledgment and encouragement from osteopathic sources than from nonosteopathic educators and organizations. ${ }^{15}$

\section{A proposal}

Toward this end, I propose that the Association of American Colleges of Osteopathic Medicine (AACOM) be asked to organize an interprofessional council of medical educators, scholars, and specialists in such disciplines as public health, community medicine, preventive medicine, and epidemiology. The council would identify the following:

- the health needs of the nation that are not being met, especially in the areas of disease prevention and health promotion (which, after all, is the most comprehensive and effective form of preventive medicine);

- the opportunities open to the osteopathic medical profession to meet those needs because of its traditions, orientation, perspectives, and methodology; and

- the steps to be taken by the profession to prepare itself for this role.

The AACOM has already made a seminal start in this process through its selection of
John Gordon Freymann, MD, as the keynote speaker at a recent educational conference. ${ }^{16}$ Dr Freymann is a distinguished medical educator and a widely recognized authority in family medicine, community medicine, and healthcare in general. In his address, he exhorted the profession to "set forth on what could become the great odyssey of osteopathic medicine," that of leading the changes in healthcare that are required to meet the needs of society. The need that he perceived and documented in his address is for transition "from hospital-based specialty services that are oriented to the cure of disease to communitybased primary care that is oriented toward prevention of disease and health maintenance."

The next generation, Dr Freymann went on to say, must be prepared for that role, but unfortunately most allopathic academic medical centers are "infatuated" with high-technology tertiary care rather than personal, primary care. Without minimizing the "miracles" of specialty medicine, he reemphasized that our greatest need is "to strike a realistic balance between high-tech medicine and disease prevention and health maintenance." (Incidentally, this is precisely the "balance" called for in 1980 by the "bold" college of osteopathic medicine referenced earlier. ${ }^{14}$

Dr Freymann's challenges to the profession were mainly in the area of postgraduate education: to develop techniques and programs of postgraduate education that focus principally on ambulatory care and that will produce a "generic primary physician," defined in the article. Dr Freyman's address merits careful study by the profession and its teachers.

In an editorial ${ }^{17}$ accompanying Dr Freymann's published address, George W. Northup, DO, Editor Emeritus of the AOA, stated that Dr Freymann had directed the profession's attention to its "innermost self," which is "not always in synch with the external 'face'." The challenges set forth in that address, Dr Northup went on to say, "present the osteopathic profession with opportunities to excel in areas suited to our heritage." Never has that heritage been more needed and more timely.

\section{From defending to leading}

In reflecting on that heritage, the osteopathic 
medical profession would be reminded that it came into existence for the very purpose of leading a transition, a reform in medicine; that it was founded to bring something else into medicine, and not just something more. That transition, to the something else identified in articles previously cited and most recently in Dr Freymann's address, is urgent and timely because it would begin to address today's greatest health needs more effectively and comprehensively than they are being met today or in the foreseeable future. The shift that is sought is from almost total preoccupation with too-late, high-cost, high-technology treatment of advanced disease toward primary care that is oriented toward prevention, especially by the maintenance and promotion of health.

In order to assume such leadership, the osteopathic medical profession needs to shake off its long-held defensive posture. Defensiveness has been engendered, in large part, by its relative newness on the medical scene, by the endless need to explain itself (that is, defend its departure from orthodoxy), by its minority status and limited resources. Defensive behavior has been sustained by the profession's willingness, in the course of explaining itself, to being drawn into irrelevant comparisons with the dominant long-established allopathic medical profession - comparisons made with allopathic rather than osteopathic criteria.

As a consequence, much of the osteopathic medical profession's power has been dissipated in "catching up" with the allopathic medical profession (eg, in diversity of technical modalities and specialties), at the cost of "getting ahead" with the osteopathic agenda. The osteopathic medical profession needs to speak for itself and about what it seeks to accomplish on behalf of the nation's health, and how its principles, methods, facilities, educational programs, and so forth would serve to meet the unmet health needs of the American people.

While continuing to be "against" disease, the osteopathic medical profession must remember and proclaim that opposition to disease is not the same as the affirmation of health, any more than opposing war is enough to bring peace. As the fastest growing profession, the osteopathic medical profession has developed a correspondingly powerful voice. It is time that the profession used that voice in the advocacy of health; in speaking courageously and unequivocally in support of policies and practices that promote health and against those that diminish it-instead of remaining discreetly and safely silent on seemingly controversial issues.

The osteopathic medical profession must use its voice to declare, with all the authority at its command, that policies and practices that diminish the health of the American people are absolutely intolerable and unacceptable, especially in view of the fact that we have the knowledge and the means to change them. Therefore, let us declare that we view it as intolerable:

- that poisoning and other degradation of our air, water, and soil is permitted to continue.

- that approximately one fifth of the American people, including millions of children, have little or no access to healthcare for economic reasons.

- that healthcare financing is almost entirely for established, late-stage, and terminal disease, and so little is for prevention.

- that so much is invested in desperately prolonging the last year or two of life, and so little to maintain and enhance health in decades yet to come.

- that so much is invested in diagnosis and treatment of victims of the chronic degenerative diseases while so little is done to divert the tens of millions of others from life paths and circumstances that culminate in the same diseases.

The osteopathic medical profession must be prepared to follow these declarations with recommendations of effective corrective measures.

The osteopathic medical profession needs to use its voice to explain to the American people how osteopathic perspectives of health and disease and the methodology selected and designed to implement those perspectives contribute to the maintenance, enhancement, and recovery of health; to teach the crucial importance of the inherent health-maintaining and health-restoring powers of the human body, and the respective roles of the individual and

(continued on page 837) 

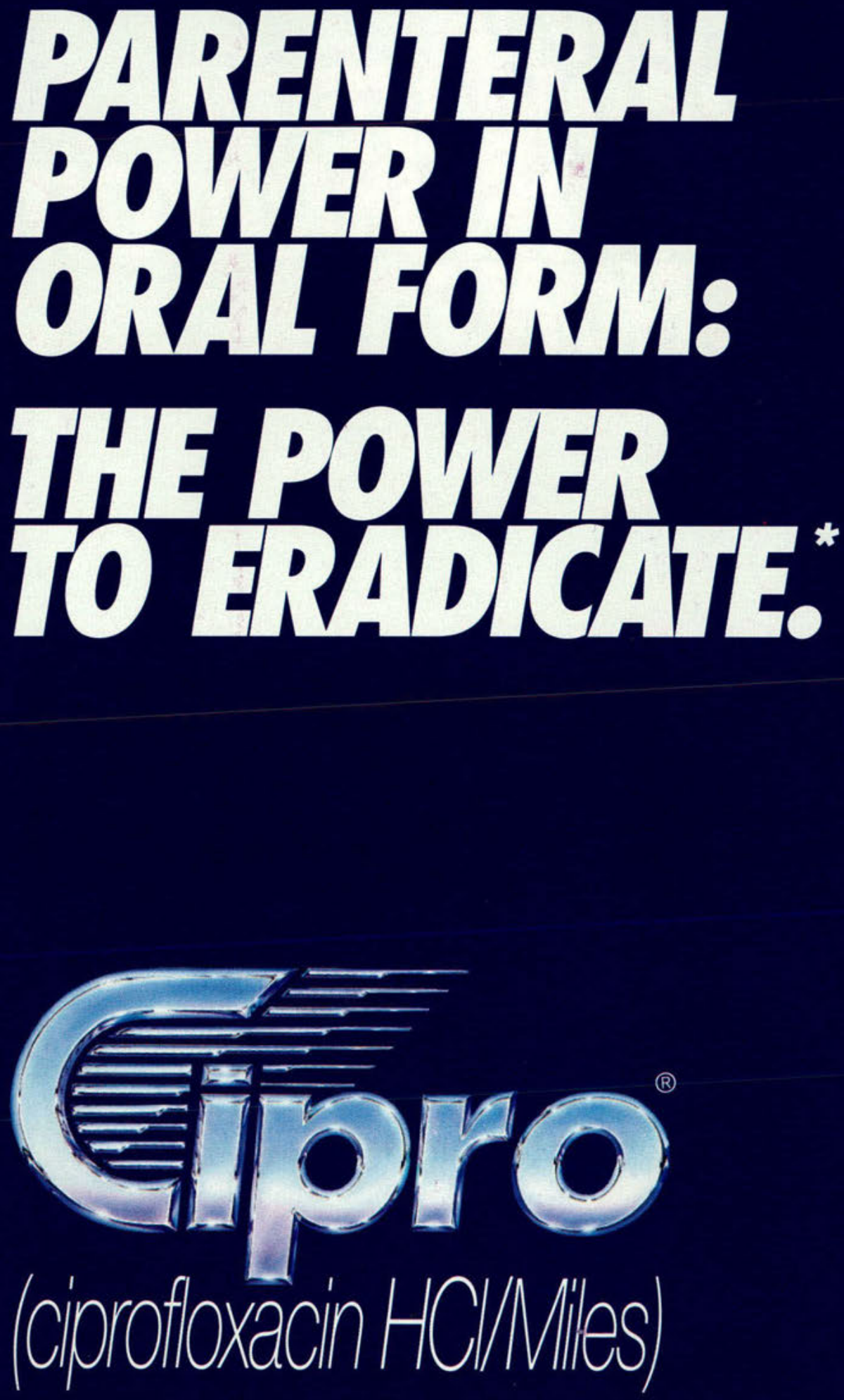

- Achieves $96 \%$ favorable clinical response (resolution + improvement) of infections due to susceptible

(B) 


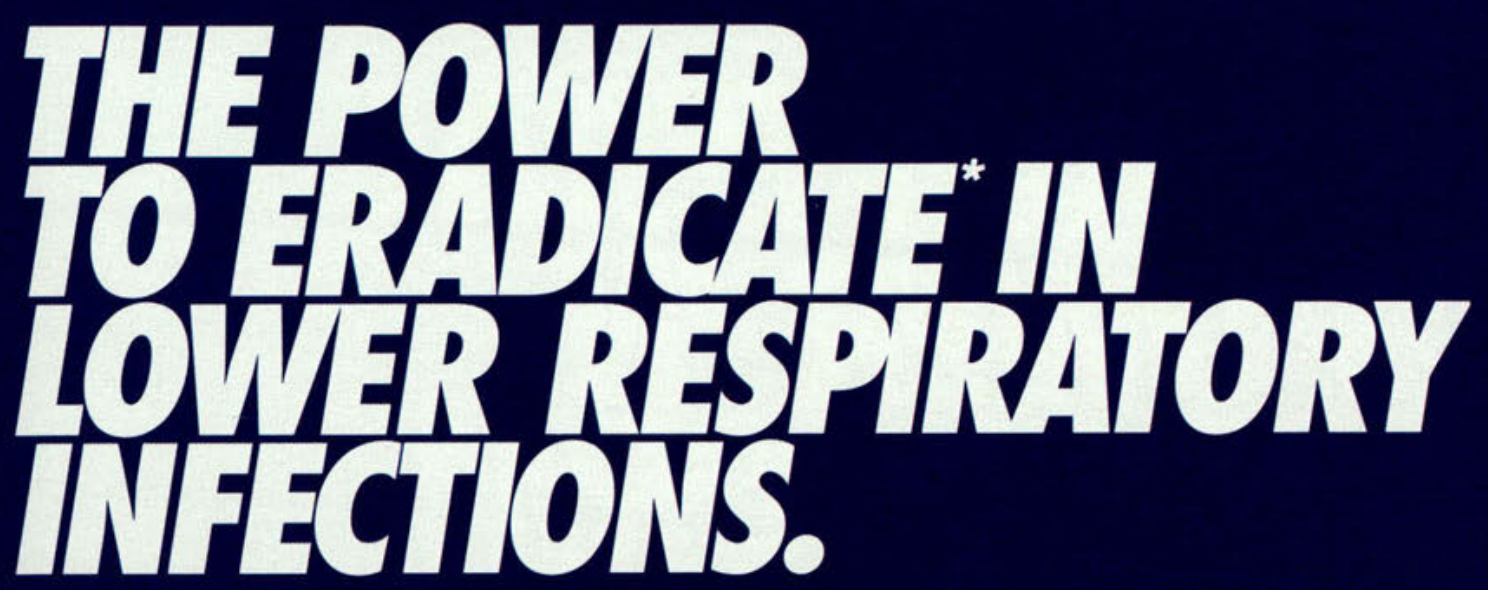

Power that achieves $96 \%$ favorable results in lower respiratory infections. ${ }^{1 \star \dagger}$

Power that destroys respiratory pathogens in vitro that are not covered by cefaclor, cephalexin, or ampicillin. ${ }^{2 \cdot 4 *}$

Power that demonstrates significant activity even against organisms resistant to other agents, such as $\mathrm{H}$. influenzae and the Enterobacteriaceae. ${ }^{1,5-7 *}$

Power that's well tolerated and is comparable in cost with cefaclor and amoxicillin/clavulanate potassium. ${ }^{8}$

NOTES: Concurrent administration of ciprofloxacin with theophylline may lead to elevated plasma concentrations of theophylline and prolongation of its elimination half-life. This may result in increased risk of theophylline-related adverse reactions. If concomitant use cannot be avoided, plasma levels of theophylline should be monitored and dosage adjustments made as appropriate.

Antacids containing magnesium hydroxide or aluminum hydroxide interfere with the absorption of ciprofloxacin, resulting in serum and urine levels lower than desired; concurrent administration of these agents with ciprofloxacin should be avoided. A history of hypersensitivity to ciprofloxacin is a contraindication to its use.

A history of hypersensitivity to other quinolones may also contraindicate the use of ciprofloxacin.

CIPRO' SHOULD NOT BE USED IN CHILDREN, ADOLESCENTS, OR PREGNANT WOMEN.

\section{The eradicator:*}
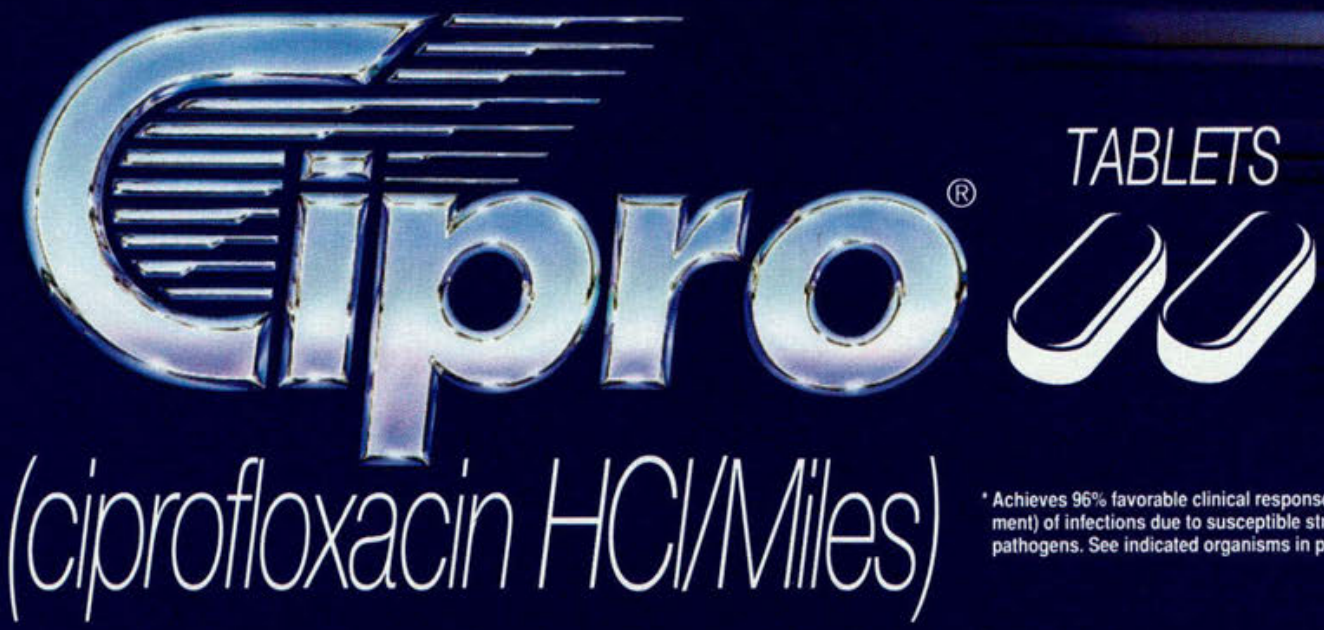

Achieves $96 \%$ favorable clinical response (resolution + improvement) of infections due to susceptible strains of indicated pathogens. See indicated organisms in prescribing intormation. 
$\checkmark$ 


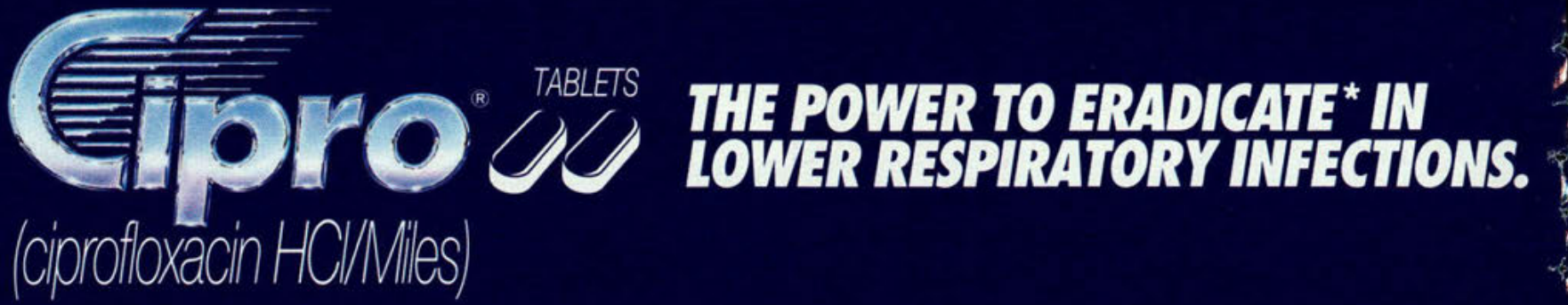

CIPRO* TABLETS

(ciprofloxacin $\mathrm{HCl} / \mathrm{Miles}$ )

BRIEF SUMMARY

CONSULT PACKAGE INSERT FOR FULL PRESCRIBING INFORMATION

INDICATIONS AND USAGE

Cipro* is indicated for the treatment of intections caused by susceptible strains of the designated microorgan sms in

the conditions listed below: mirabilis, Pseudomonas aeruginosa. Haemophilus influenzae. Haemophilus parainfluenzae, and Streptococcus

Sneumonal Skin Structure Intections caused by Escherichia coll. Klebsiella pneumoniae. Enterobacter cloacae. Proteus mirabilis. Proteus vulgaris. Providencia stuartui. Morganella morganin. Citrobacter freundiv. Pseudomonas aeruginosa. Staphylococcus aureus. Staphylococcus epidermidis, and Streptococcus pyogenes

Bone and Joint Infections caused by Enterobacter cloacae. Serratia marcescens, and Pseudomonas aeruginosa. Urinary Tract Inlections caused by Escherichia coli. Klebsiella pneumoniae. Enterobacter cloacae. Serratia mar. cescens. Proteus mirabilis. Providencia rettgeri. Morganella morganii. Citrobacter diversus. Citrobacter freundiv. Pseudomonas aeruginosa. Staphylococcus epidermidis. and Streptococcus faecalis

Infectious Diarthea caused by Escherichia coli (enterotoxigenic strains). Campylobacter jejuni. Shigella flexner and Shigella sonner' when antibacterial therapy is indicated

"Etficacy for this organism in this organ system was studied in tewer than 10 infections CONTRAINDICATIONS

A history of hypersensitivity to ciprofloxacin is a contraindication to its use. A history of hypersensitivity to other quinolones may also contraindicate the use of ciprofloxacin.

CIPROFLOXACIN SHOULD NOT BE USED IN CHILDREN. ADOLESCENTS, OR PREGNANT WOMEN. The oral administration of ciprofloxacin caused lameness in immature dogs. Histopathoiogical examination of the weight-bearing joints of these dogs revealed permanent lesions of the cartilage. Related drugs such as nalidixic acid. cinoxacin, and nortloxacin also produced erosions of cartilage of weight bearing joints and other signs of arthropathy in immature animals of various species (SEE ANIMAL PHARMACOLOGY SEC General: As with other qunolones. ciprofloxacin may cause central nervous system (CNS) stimulation, which may
lead to tremor, restlessness. 1 ghtheadedness. confusion. and rarely to hallucinations or convulisive sezures. Theretore. ciprofloxacin should be used with caution in patients with known or suspected CNS disorders, such as severe fore. ciprofloxacin should be used with caution in patients with known or suspected CNS disorders, SUCh as seve
cerebral arterioscierosis or eplepsy. or other factors which predispose to seizures (SEE ADVERSE REACTIONS).

Anaphylactic reactions following the first dose have been reported in patients receiving therapy with quinolones. Some reactions were accompanied by cardiovascular collapse, loss of consciousness. tingling. pharyngeal or tacia edema. dyspnea, urticaria, and itching. Only a few patents had a history of hypersenstivity reaction. Anaphylactic sign of hypersensitivity or allergy.

Severe hypersensitivity reactions characterzed by rash. tever eosinophilia. jaundice, and hepatic necrosis wth tatal outcome have been reported rarely (less than one per million prescriptions) in patients receiving ciprofloxacin along with other drugs. The possibility that these reactions were related to ciprofloxacin cannot be excluded. Ciprofloxacin should be discontinued at the first appearance of a skin rash or any sign of other hypersensitivity reaction

Crystals of ciprotioxacin have been observed rarely in the urine of human subjects but more frequently in the urine

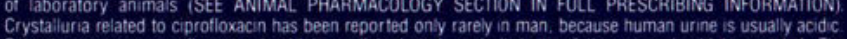
Crystalluria related to ciprotloxacin has been reported ony rarey in man, because human urine is usualy acidic
Patients receiving ciprofloxacin should be well hydrated. and alkalinity of the urine should be avoided. The Patents receiving ciprofloxacin should be weil

Ateration of the dosage regimen is necessary for patients with impairment of renal function (SEE DOSAGE AND Aiteration of the
ADMINISTRATION)

As with any potent drug. periodic assessment of organ system functions, including renal, hepatic. and in advisable during prolonged theraas

Orug Interactions: As with other quinoliones. concurrent administration of ciprofloxacin with theophylline may lead to elevated plasma concentrations of theophylline and prolongation of its elimination hatif-ife. This may result in micreased risk of theophylline-related adverse reactions. If concomitant use cannot be avoided. plasma levels of heophy inte shoud be monitored and dosage adjustmentis made as appropria

lead to reduced clearance of catteine and a prolongation of its plasma half-itite

ad to reduced clearance of calteine and a prolongation of its pasma haif-lite. Antacids containing magnesim hydroxide or aluminum hydroxide may intertere with the absorption of ciprofiox-
acin resulting in serum and unine levels lower than desired. concurrent administration of these agents with ciprofloxacin should be avoided

Concomitant administration of the nonsteroidal anti-inflammatory drug fenbuten with a quinolone has been reported to increase the risk of CNS stimulation and convulsive sezures

Probenecid interferes with the renal tubular secretion of ciprofloxacin and produces an increase in the level of ciprofloxacin in the serum. This should be considered if patients are receiving both drugs concomitantly

As with other broad-spectrum antibiotics. prolonged use of ciprofloxacin may result in overgrowth of nonsuscept. ble organisms. Repeated evaluation of the patent's condition and microbial susceptibility testing is essential. If superintection occurs during therapy. appropriate measures should be taken

Information for Patients: Patients should be advised that ciprofloxacin may be taken wth or without meals. The preferred time of dosing is two hours after a meal. Patients should also be advised to drink fluids liberally and not take Patents should he advised that aluminum

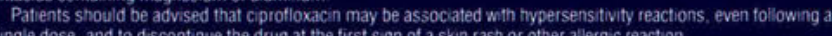
gle dose, and to discontinue the diug at the first sign of a skin rash or other allergic reactio

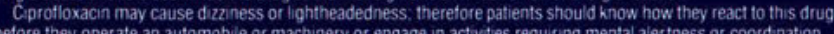

Patients should be advised that ciprofloxacin may increase the effects of theophylline and catteine.

Carcinogenesis, Mutagenesis. Impairment of Fertility: Eight in vitro mutagenicty tests have been conducted with ciprofloxacin and the test results are listed below:

Saimonella Microsome Test (Negative)

E. coll DNA Repar Assay (Negative)

Mouse Lymphoma Cell Forward Mutation Assay (Positive)

Chinese Hamster $\mathrm{V}_{79}$ Cell HGPRT Test (Negative)

Syrian Hamster Embryo Cell Transtormation Assay (Negative)

Saccharomyces cerevisiae Point Mutation Assay (Negative)

Saccharonimces cerevisiae Mitotic Crossover and

Thus. fwo of the eight tests were positive, but the results of the following three in vivo test systems gave negative

Rat Hepatocyte ONA Repair Assa

Micronucleus Test (Mice)

Long-term carcinogenicity studies in rats and mice have been completed. Atter daly oral dosing for ip to 2 vears. there is no evidence that ciprofloxacin had any carcinogenic or tumorigenic effects in these speces

Pregnancy-Pregnancy Category C. Reproduction studies have been performed in rats and mice at doses up to 6 times the usual dally human dose and have revealed no evidence of impaired fertility or harm to the fetus due to ciprofloxacin. In rabbits, as with most antimicrobial agents. ciprofloxacin (30 and $100 \mathrm{mg} \mathrm{kg}$ orally) produced
gastrointestinal disturbances resulting in maternal weight loss and an increased incidence of abortion. No terato- genicity was observed at either dose. After intravenous administration. at doses up to $20 \mathrm{mg} / \mathrm{kg}$, no maternal toxicity was produced, and no embryotoxicity or teratogenicity was observed. There are, however, no adequate and well controlled studies in pregnant women. SINCE CIPROFLOXACIN. LIKE OTHER DRUGS IN ITS CLASS. CAUS Nursing Mothers: It is not known whether ciprofloxacin is excreted in human milk, however if is known tha: ciprotloxacin is excreted in the milk of lactating rats and that other drugs of this class are excreted in human mik decause of this and because of the potential for serious adverse reactions from ciproiloxacin in nursing intants. drug to the mother

Pediatric Use: Patients under the age of 18 were not included in the clinical trials of ciprofloxacin because cprofloxacin as well as other quinolones causes arthropathy in immature animals. Ciprofloxacin should not be used n children or adolescents (SEE WARNINGS

\section{ADVERSE REACTIONS}

Gprofloxacin is generally well tolerated. During clinical investigation. 2.799 patients receved 2.868 courses of the drug. Adverse events that were considered likey to be drug related occurred in $7.3 \%$ of courses. possiby related in

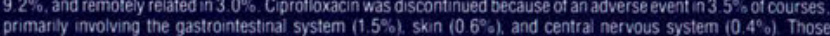
primarily involving the gastrointestinal s

The most frequently reported events, drug related or not, were nausea $(5.2 \%)$. diarrhea $(2.3 \%)$, vomiting $(2.0 \%)$. bdominal pain discomfort $(1.7 \%)$, headache $(1.2 \%)$, restlessness $(1.1 \%)$, and rash $(1.1 \%$

GASTROINTESTINAL: (See above), painful oral mucosa, oral candidiasis, dysphaga, intestinal perforation gastrointestinal bleeding.

CENTRAL NERVOUS SYSTEM: (See above), dizziness. lightheadedness, insomnia, nightmares, hallucina: ons. manic reaction. irritability, tremor, ataxia, convulsive serzures. lethargy, drowsiness, weakness. ma: aise. anorexia, phobia, depersonalization, depression, paresthesi

ShiN HFensensif angioedema. edema of the face. neck. lips. conjunctivae or hands. cutaneous candidiasis, hyperp:gmentation erythema nodosum

A ergc reactions ranging from urticaria to anaphylactic reactions have been reported (SEE PRECAUTIONS SPECIAL SENSES blurred vision. disturbed vision (change in color perception. overbrightness of lights) decreased visual acuity. diplopia. eye pain, tinnitus, hearing loss, bad tast:

DENAL L

RENAL UROGENITAL: interstitial hephintis, nephritis, renal failure. polyuria. urinary retention, urethra bleeding, vaginitis, acidosis

CARDIOVASCULAR: paipitations, atrial flutter, ventricular ectopy, syncope, hypertension, angina pectoris myocardial intarction. cardiopulmonary arrest. cerebral thrombosis.

RESPIRATORY: epistaxs. laryngeal or puimonary edema, hiccough, hemoptysis. dyspnea. bronchospasm puimonary embolism

Irost or the adverse events reported were described as only mild or moderate in severity. abated soon atter the rug was discontinued. and required no treatme:

In several instances. nausea. vomiting. tremor. restlessness. agtation, or palpitations were judged by in vestigators to be related to eievated plasma levels of theophylline possibly as a result of a drug interaction with Other adverse

syndrome, exfolative dermatits, toxic epidermal necro psis, hepatic necrosis, postural hypotension, possible exac erbation of myasthenia gravis. confusion. dysphasia. nystagmus, pseudomembranous colitis, dyspepsia fiatulence, and constipation. Also reported were agranulocytosis: elevation of serum triglycerides. serum cholesterol, biood glucose. serum potassium: proico
candidasis and renal caiculi (SEE PRECAUTIONS)

Adverse Laboratory Changes: Changes in laboratory parameters listed as adverse events without regard to drug relationship

Hepatic-Elevations of: ALT (SGPT) (1.9\%). AST (SGOT) (1.7\%), alkaline phosphatase $\left(0.8^{\circ} \%\right)$. LDH $(0.4 \%)$ serum bilirubin $10.3 \%$

Cholestatic jaundice has been reporte

Hematologic-Eosinophilia $(0.6 \%)$. leukopena $(0.4 \%)$. decreased blood platelets $(0.1 \%)$, elevated bioo platelets $(0.10)$ pancytopenia $(0.1 \%$

Renal-Elevations of Serum creatinine $(1.1 \%)$. BUN $(0.9 \%)$

CRYSTALLURIA. CYLINORURIA. AND HEMATURIA HAVE BEEN REPORTED

Other changes occurring in less than $0.1 \%$ of courses were: Elevation of serum gammagiutamyl transterase elevation of serum amylase. reduction in blood glucose. elevated uric acid. decrease in hemoglobin. anemia bleeding diathesis. increase in biood monocytes, and leukocytosis
OVERDOSAGE

Information on overdosage in humans is not avaliable. In the event of acute overdosage, the stomach should be emptied by inducing vomiting or by gastric lavage. The patient should be carefully observed and given supportive
treatment. Adequate hydration must be maintained. Only a small amount of ciprofloxacin ( $10 \%$ ) is removed from the body after hemodalysis or peritoneal dialysis

\section{DOSAGE AND ADMINISTRATION}

The usual adult dosage for patients with urinary tract infections is $250 \mathrm{mg}$ every 12 hours. For patients with complicated infections caused by organisms not highly susceptible. $500 \mathrm{mg}$ may be admin stered every 12 hours. Lower respiratory tract infections. Skin and skin structure infections. and bone and joint intections may be treated with 500
hours.
The :

The recommended dosage for infectious darrhea is 500 mo every 12 hours

In patients with renal impairment. Some modification of dosage is recommended ISEE DOSAGE AND AD: MINISTRATION SECTION IN FULL PRESCRIBING INFORMATION)

HOW SUPPLIED Cipro* (cprofloxacin HCI Miles) is avalable as tablets of $250 \mathrm{mg} .500 \mathrm{mg}$, and $750 \mathrm{mg}$ in botties of 50 , and in Unit-
Dose packages of 100 (SEE FULL. PRESCRIBING INFORMATION FOR COMPLETE DESCRIPTION)

References: 1. Data on file, Mies Inc Pharmaceutical Division. 2. Physicians' Desk Reference: 43rd ed. Oradell, NJ. Medical Economics Co Inc; 1989:891, 1168, 1441. 2098. 3. Wollschlager CM. efal. Controlled, comparative study of ciprofloxacin versus ampicillin in treatment of bacterial respiratory tract infections. Am J Med. 1987:82(supp. 4A) $164-168$. 4. Fest $\mathrm{H}$. et al. Comparative study of ciprotloxacin and cefalexin in the treatment of patients with lower respiratory tract infections. In: Neu HC. Weuta $\mathrm{H}$, eds. Ist International Ciprofloxacin Workshop. Amsterdam. Excerpta Medica: 1986-265-267. 5. Parry MF. Quinolone resistance- trends in U.S. susceptibility data. In: Ciprofloxacin: Major Advances in Intravenous and Oral Qunolone Iherapy. Scientific Program and Abstracts. Naples. Florida:
1989-21. 6. Sanders CC et al Overview of preclinical studies with ciprofloxacin. Am.JMed 1987-82 (Supp 14A) 2-11 1989:21. 6. Sanders CC. et al. Overview of precinical studies with ciprofloxacin. Am J Med. $1987: 82$ (suppl 4A) 2-11 7. Machika K. ef al. In vitro activity of new antibiotics a
$1988,7: 812-814.8$. Redbook Update, 1989:8(5):4,6.7

Achieves $96 \%$ tavorable clinical response (resolution + improve
pathogens. See indicated organisms in prescribing intormation.

For further information, contact the Miles Information Service:

1-800-642-4776. In VA, coll collect: 703-391-7888.

COMMITTED TO THERAPEUTIC EFFICIENCY

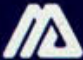

Pharmaceutical Divasion

Pharmaceutical

West Haven. CT 065

\section{8*}

人

\section{Sit}

$\frac{d}{f}$


the physician in the care and disencumbering of those indwelling powers.

And finally, the osteopathic medical profession must use its voice to teach the art of healthful living, to which the principles of osteopathic medicine are reliable guides.

Were the profession, in 1990, to begin (1) to take these steps; (2) to undertake the changes in undergraduate osteopathic medical education proposed in the preceding section; and (3) to make the changes in postgraduate education, proposed by Dr Freymann, to produce a predominance of primary physicians skilled in ambulatory care, it would, by the year 2000 , discover:

- It was the recipient of unprecedented public understanding and support.

- Its small size not only was not a disadvantage, but it also made possible the flexibility, adaptability, and maneuverability required for the leadership role.

- Many of the presently perceived shortages and handicaps (as compared with the allopathic medical profession), such as those in tertiary-care centers, high technology, and training programs for all the specialties and subspecialties, are actually assets in that they free the osteopathic medical profession from irrelevant encumbrances in its role as leader in primary, ambulatory care. As Dr Freymann states, "what has been seen as a defect in osteopathic graduate medical education can now be turned to a major advantage. Osteopathic medicine is not burdened by huge tertiary-care centers that blind staff and students to the real healthcare needs of the American people." 16

- The decline in "osteopathic" hospital beds, now viewed as disastrous, is another fortuitous advantage in preparing for leadership in primary care. As Dr Freymann points out, acute-care hospitals would serve only as adjuncts to primary care and to teaching in ambulatory care centers.
Never in its entire history has the osteopathic medical profession been presented with a greater opportunity to serve the United States and to set examples for all of medicine to follow throughout the world. It would achieve the ultimate in distinctiveness.

Appreciation is expressed to James J. Balija, director of membership and information of the American Osteopathic Association for vital statistics regarding the osteopathic medical profession and the population of the United States.

1. Northup GW: Osteopathic Medicine: An American Reformation, ed 2. Chicago, American Osteopathic Association, 1970.

2. Osteopathic Medicine. Chicago American Osteopathic Association, undated.

3. What Is a DO? What Is an MD? Chicago, American Osteopathic Association, 1987.

4. Allen TW: Correcting the misperceptions surrounding osteopathic medicine. JAOA 1990;90:128.

5. Korr IM: The function of the osteopathic profession: A matter for decision. JAOA 1959;59:77-90.

6. Yearbook and Directory of Osteopathic Physicians. Chicago, American Osteopathic Association, 1990, p575.

7. Cummings M: The pull toward the vacuum: Osteopathic medical education in the 1980s. JAOA 1990;90:353-362.

8. Aquilina $\mathrm{AD}$ : General practice residency training and the osteopathic profession: Trends and issues for the 1990s. JAOA 1990;90:1600178.

9. Chornoff R, Lipschitz DA (eds): Health Promotion and Disease Prevention in the Elderly. New York, Raven Press, 1988. 10. Korr IM: Osteopathy and medical evolution. JAOA 1962;61:515-526.

11. Korr IM: Somatic dysfunction, osteopathic manipulative treatment and the nervous system: A few facts, some theories, many questions. JAOA 1986;86:109-114.

12. Korr IM: Osteopathic principles: A way of life. The $D O$ 1987;28(5):25-27.

13. Korr IM: Medical education: The resistance to change. JAOA 1988;88:1022-1026.

14. Design of the Medical Curriculum in Relation to the Health Needs of the Nation. Fort Worth, Tex, Texas College of Osteopathic Medicine, 1980.

15. Korr IM, Ogilvie CD: Health orientation in medical education. United States: Texas College of Osteopathic Medicine. Prev Med 1981;10:710-718.

16. Freymann JG: The odyssey and outlook of graduate medical education. JAOA 1989;89:761-767.

17. Northup GW: Returning to the 'guts' of medicine. JAOA 1989;89:758. 